\title{
Morphological Indicators of the Facies of Biological Fluids in Patients with Liver Diseases
}

\author{
M.T. Botirov ${ }^{1}$ \\ ${ }^{1}$ Fergana branch, Tashkent Medical Academy, Uzbekistan \\ Correspondence: M.T. Botirov, Fergana branch, Tashkent Medical Academy, Uzbekistan. E-mail: arsif@mail.ru
}

Received: March 10, 2018

Accepted: March 31, $2018 \quad$ Online Published: March 30, 2018

doi:10.5539/ijb.v10n2p41

URL: https://doi.org/10.5539/ijb.v10n2p41

\begin{abstract}
The article discusses the results of morphometric studies of the solid phase serum of patients with liver disease. It is shown that the marker enzymes, minerals and proteins bioliquid facies (serum) obtained by dehydration wedge observed facies different zones.
\end{abstract}

Keywords: blood serum, facies, a biological fluid, a wedge-shaped dehydration, liver cirrhosis

\section{Relevance of the Work}

A few decades ago, many predicted the imminent accession of science in the age of biology. Twenty-first century has been called the century of the life sciences - including health, his longevity, place in nature. And indeed the revision of priorities in science occurred.

In Uzbekistan, along with the developed countries of the world, this process came to the government level, and was reflected in the reorientation of the socio-economic approaches, causing health and environmental problems attached particular importance - as a priority. It is significant that in the first place among scientific programs cost the budget in developed countries is biology, which hold a large amount of applied medical problems.

Biological fluids (blood, urine, saliva, etc.) Play an important role in the organism. The organisms are entire systems and mechanisms that support in the normal conditions of their composition, structure, quantity, parameters and other properties. It is found that the deviation of these parameters outside the adaptation rules always leads to pathological processes in the body at the cellular, organ or system level (Shabalin \& Shatokhina, 2001).

Changing the parameters of body fluids can occur either as a result of external causes or effects, either as a result of failures in the components of the organism. In any case, the parameters and properties of body fluids are indicative of the state of health as its individual elements as well as whole body (Shatokhina, 1995).

The purpose of the study was to examine the features of the system of organization and identification of serum markers of healthy and sick people with liver disease.

\section{Materials and Methods}

To achieve the objectives for the period from 2012 to 2014, the method of wedge dehydration, solid phase serum were obtained of 283 patients (137 males, females, 146) at different ages, with viral liver disease (total 225 patients, of whom 111 in acute, chronic period 104), with liver cirrhosis (68 patients in all stages of a, B, C by Child Pugh) and 51 healthy people. All patients were treated at the Ferghana regional infectious diseases hospital and Fergana regional diversified medical centers.

Clinical diagnoses were established physicians of medical institutions where patients are treated on the basis of patients' complaints, medical history, typical clinical picture, the results of clinical, biochemical, immunological tests and imaging studies. The diagnosis was in accordance with the existing classifications for International Classification of Diseases - ICD-10.

Structural analysis of the blood serum of patients was conducted by the method of wedge dehydration. a control group of healthy people (according to the medical certificate of military enlistment offices and medical form 086 / y) was taken for comparison facies crystals of biological fluids (BF) aged 17-30 years. Determine the types of facies classification V.N. Shabalin and S.N. Shatokhina (Shabalin \& Shatokhina, 2002). 
Crystallographic picture of dried droplets (facies) was investigated using a stereo microscope Leica Magnum - T $2721 \mathrm{c}$ photosystem MPS 60. Facies image processing performed on the computer program "ExterNET AMI systems" (Abdumanonov, Botirov, \& Karabaev, 2014).

\section{Results and Discussion}

Analysis blood serum crystallographic features let highlight 4 types of its structural organization in the pathology of the liver: partly radial, irradialny, circulatory and "three-fold".

The first type - partly radial had mild to moderate deviations from the radial-ordered arrangement of sectors, individual and nodules (Figure 1a.).

The second type - irradialny characterized by significant impairment on the systemic level. Figure facies characterized by asymmetry, the number of basic elements have been reduced, and their configuration is varied (Figure $1 \mathrm{~b}$ ).

A feature of the third type - circulatory was the presence of large cracks, are arranged parallel to the edge facies between the peripheral and intermediate zones, the formation of which is determined by the circular distribution of the observed basic structures (Fig c.).

The structural pattern of the fourth type, is fundamentally different from the above types of facies serum did not contain the basic elements of her drawing was created by a network of small convoluted (three-prong) cracks that gave us a reason to call this type of "three-beam" (Figure 1g).

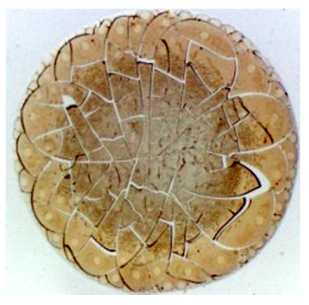

a

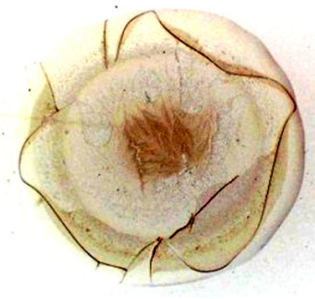

b

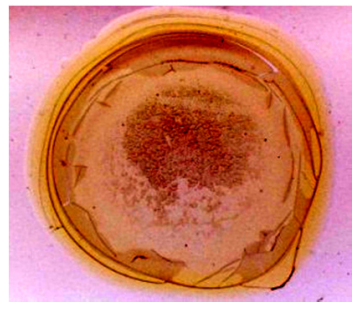

c

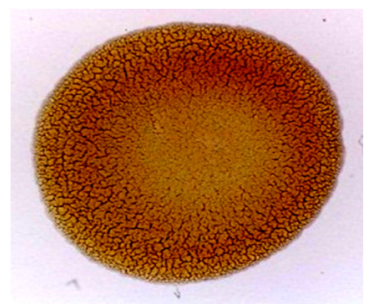

g

Figure 1. The types of structural organization of serum liver diseases

The distribution of facies types of blood serum in patients examined is shown in Table 1 .

Table 1. Facies types of blood serum liver diseases

\begin{tabular}{lllllllll}
\hline \multirow{2}{*}{ Facies type } & \multicolumn{2}{l}{$\begin{array}{l}\text { acute viral hepatitis } \\
(\mathrm{n}=111)\end{array}$} & \multicolumn{2}{l}{$\begin{array}{l}\text { chronic hepatitis } \\
(\mathrm{n}=104)\end{array}$} & \multicolumn{2}{l}{$\begin{array}{l}\text { cirrhosis of the liver } \\
(\mathrm{n}=68)\end{array}$} & \multicolumn{2}{l}{$\begin{array}{l}\text { Control } \\
(\mathrm{n}=51)\end{array}$} \\
\cline { 2 - 11 } & $\mathrm{abc}$ & $\%$ & $\mathrm{abc}$ & $\%$ & $\mathrm{abc}$ & $\%$ & $\mathrm{Abc}$ & $\%$ \\
\hline Partially groove & - & - & - & - & - & - & 51 & 100 \\
Irradialny & 45 & 40.5 & 54 & 51.9 & 45 & 66.2 & - & - \\
Circulatory & 30 & 27 & 32 & 30.8 & 16 & 23.5 & - & - \\
Three-prong & 36 & 32.4 & 18 & 17.3 & 7 & 10.3 & - & - \\
\hline
\end{tabular}

Thus, the serum of patients in the study using the method of wedge dehydration, with significant differences from the norm, is characterized by the presence of at least one of the major structural elements (large cracks, sectors, individual or nodules).

In addition to the identified changes in the main items of the facies in the structural organization of the serum examined patients determined a wide variety of abnormal structures.

Analysis of the results revealed the most typical and most common abnormal structure with cirrhosis who were treated leaf structure and various types of cracks, concentration, etc. are free. The hallmark of facies blood serum in liver disease was pathologically modified polymorphism cracks. There were cracks circulatory, knotted blocks, the structure of the "harness" in the central area and the periphery.

In the spectrum of the most frequently detected violations of local structural organization of the blood serum with liver cirrhosis leading position occupied by leaf-shaped structure, is a sign of sclerosis process, tri-radial cracks markers of stagnation. 
Our results showed that leaf-shaped structure was significantly more common with cirrhosis than in patients with chronic hepatitis and moss figure rounded circular crack on and recorded at approximately the same frequency.

It is known that the pattern being the level of blood serum reflects the degree of tension of adaptive systems of the body: the pronounced adaptive response, the higher the activity of structure. In addition to the basic elements of the identified changes facies in crystallographic picture of blood serum of patients examined was determined by a wide variety of abnormal patterns (Table 2).

Table 2. The frequency of abnormal structures in the morphological picture of blood serum in liver disease

\begin{tabular}{|c|c|c|c|c|c|c|c|c|}
\hline \multirow{3}{*}{$\begin{array}{l}\text { Pathological } \\
\text { structure }\end{array}$} & \multicolumn{8}{|c|}{ Groups of patients } \\
\hline & \multicolumn{2}{|c|}{$\begin{array}{l}\text { Acute Viral Hepatitis } \\
\qquad(\mathrm{n}=111)\end{array}$} & \multicolumn{2}{|c|}{$\begin{array}{c}\text { chronic hepatitis } \\
\quad(\mathrm{n}=104)\end{array}$} & \multicolumn{2}{|c|}{$\begin{array}{l}\text { cirrhosis of the liver } \\
\qquad(\mathrm{n}=68)\end{array}$} & \multicolumn{2}{|c|}{$\begin{array}{c}\text { Norm } \\
(\mathrm{n}=51)\end{array}$} \\
\hline & abs. & $\%$ & abs. & $\%$ & abs. & $\%$ & abs. & $\%$ \\
\hline Dendrites & 58 & 52.2 & 101 & 97.1 & 15 & 22.1 & - & - \\
\hline spherulites & 20 & 18.0 & 18 & 17.3 & 2 & 2.9 & - & - \\
\hline Whiskers & - & - & - & - & 5 & 7.4 & - & - \\
\hline defective spherulite & - & - & 2 & 1.9 & 18 & 26.5 & - & - \\
\hline Dual facies & 20 & 18.0 & 35 & 33.6 & 4 & 5.9 & - & - \\
\hline Rounded inclusion & 28 & 25.2 & 48 & 46.2 & 25 & 36.8 & - & - \\
\hline Circular waves & - & - & 10 & 9.6 & 17 & 25 & - & - \\
\hline Asymmetric separately located & 58 & 52.3 & 104 & 100 & 6 & 8.8 & - & - \\
\hline Arcade-radial cracks & - & - & - & - & 10 & 14.7 & 51 & 100 \\
\hline concentration wave & - & - & - & - & 8 & 11.8 & - & - \\
\hline Local concentration waves & - & - & - & - & 2 & 2.9 & - & - \\
\hline The funnel-shaped cracks & - & - & - & - & - & - & 40 & 78.4 \\
\hline Wrinkles & - & - & - & - & 17 & 25 & - & - \\
\hline blur effect & 10 & 9.0 & - & - & 4 & 5.9 & - & - \\
\hline Blyashkoobraznye structure & - & - & - & - & 10 & 14.7 & - & - \\
\hline The structure of the "harness" & - & - & 48 & 46.1 & 14 & 20.6 & - & - \\
\hline Circular cracks & - & - & 55 & 52.9 & 30 & 44.1 & 45 & 88.2 \\
\hline nodules & 31 & 27.9 & 68 & 65.4 & - & - & - & - \\
\hline The structure of the "harness" on the periphery & 58 & 52.3 & 104 & 100 & 22 & 32.3 & - & - \\
\hline The structure of "tow" in the central zone of the type & 58 & 52.3 & 104 & 100 & 35 & 51.5 & - & - \\
\hline Moss & 75 & 67.6 & 104 & 100 & 68 & 100 & - & - \\
\hline leaflike structure & - & - & - & - & 26 & 38.2 & - & - \\
\hline crack three-beam & 10 & 9.0 & 15 & 14.4 & 49 & 72.1 & - & - \\
\hline Availability zones & 90 & 81.1 & 100 & 96.1 & 60 & 88.2 & 51 & 100 \\
\hline
\end{tabular}

As Table 2 shows that the dendrites enable rounded asymmetrical spaced apart, such as "plait" structure at the periphery and in the central zone occurs in a large amount (more than $50 \%$ cases) during the acute and chronic hepatitis. Circular cracks structure "harness" the type of circular waves, defective spherulites occur in chronic hepatitis and liver cirrhosis. Figures in the form of a "Mocha" and the presence of the zones found in all patients in the facies of blood serum. Zoning is available in all facies of patients examined. Measurement of the diameters of zones, shows that the relationship between them is almost the same in all cases.

We were the first in liver disease have been found, "moss" figure is a sign of increasing concentration of bilirubin in the blood. The figure of "moss" facies in serum in chronic liver disease and cirrhosis of the liver occurs $100 \%$. The emergence of these types of crystals in the blood serum of patients mainly due to the increase in bilirubin, ALT, AST, and total protein. This is confirmed by the testimony of the biochemical laboratory of the Fergana regional infectious diseases hospital.

As a result of our research found that increasing excess of bilirubin (normal bilirubin 8.53-20.5 mmol / 1), moss area of the figure is increased by $3,4 \pm 0,3 \mathrm{~mm} 2$. Thus, we can say that the blood bilirubin appears in the central area of its dried solid phase in the form of figures "Moss" type area that clearly correlates with the quantity (Botirov, Abdumanonov, \& Karabaev, 2013). 
It has been shown that more frequent during cirrhosis of the liver than in acute viral hepatitis and chronic hepatitis leaf, tri-radial cracks, and rounded on and circulatory crack recorded at approximately the same frequency. The incidence of the structure of the "harness" in the central zone of facies that are considered dehydration marker in chronic hepatitis was higher than in acute viral hepatitis and liver cirrhosis.

\section{Conclusions}

1) The blood serum of patients in the study using the method of wedge dehydration, with significant differences from the norm, is characterized by the presence of at least one of the major structural elements (large cracks, sectors, individual or nodules). In addition to the identified changes in the main items of the facies in the structural organization of the serum examined patients determined a wide variety of abnormal structures.

2) Revealed the most typical and most common abnormal structure with cirrhosis who were treated leaf structure and various types of cracks, concentration, etc. are free. The hallmark of facies serum in liver disease was pathologically modified polymorphism cracks. There were cracks circulatory, knotted blocks, the structure of the "harness" in the central area and the periphery.

3) It was found that the leaf structure was significantly more common with cirrhosis than in chronic hepatitis and moss figure rounded circular crack on and recorded at approximately the same frequency.

4) We were the first in liver disease have been found, "moss" figure is a sign of increasing concentration of bilirubin in the blood.

\section{References}

Abdumanonov, A. A., Botirov, M. T., \& Karabaev, M. K. (2014). Development of computer programs and algorithms for automatic morphometry bioliquid facies. New look. International Scientific Gazette, (6).

Botirov, M. T., Abdumanonov, A. A., \& Karabaev, M. K. (2013). Diagnostic informativeness crystallographic imaging of biological fluids and their computer recognition. Prospects of development of information technologies, (12).

Shabalin, V. N., \& Shatokhina, S. N. (2001). Morphology of biological fluids. Khrisostom, Moscow, 304.

Shabalin, V. N., \& Shatokhina, S. N. (2002). Morphology of biological fluids in clinical laboratory diagnosis. Klinicheskaia laboratornaia diagnostika, (3), 25.

Shatokhina, S. N. (1995). Diagnostic value of the crystal structures of biological fluids in the clinic of internal diseases: Dis. dokt. honey. nauk.

\section{Copyrights}

Copyright for this article is retained by the author(s), with first publication rights granted to the journal.

This is an open-access article distributed under the terms and conditions of the Creative Commons Attribution license (http://creativecommons.org/licenses/by/4.0/). 